\title{
Los sentidos del lugar. Temporalidades, relaciones sociales y memorias en un barrio segregado de La Plata (Argentina)
}

\author{
Ramiro Segura \\ Doctor en Ciencias Sociales (Universidad Nacional de General Sarmiento) \\ Profesor Adjunto en la Universidad Nacional de La Plata \\ La Plata, Argentina \\ segura.ramiro@gmail.com
}

\begin{abstract}
Resumen A partir del trabajo etnográfico en "Puente de Fierro", barrio segregado y estigmatizado de la periferia de la ciudad de La Plata (Argentina), el presente artículo analiza el proceso de atribución de sentidos por medio del cual un "espacio" deviene "lugar". Se detiene en dos aspectos fundamentales para comprender los sentidos del lugar. Por un lado, describe el habitar como proceso social, espacial y temporal de construcción de vínculos con el espacio y con otros actores sociales. Por el otro, analiza dos proyectos contemporáneos (uno sobre la "memoria", otro sobre el "patrimonio") que buscan revertir los sentidos dominantes sobre el lugar. El "lugar" consiste en un espacio de entrecruzamientos, diálogos y conflictos entre diversos actores a lo largo del tiempo, así como condición, objeto y producto de estas relaciones. Se trata de un proceso abierto e inacabado, con sentidos cambiantes, alternativos o en disputa.
\end{abstract}

Palabras clave: lugar, habitar, temporalidades, relaciones, memoria

\section{Introducción}

Duente de Fierro es un lugar. Al menos para quienes habitan en la Ciudad de La Plata (Argentina), Puente de Fierro es un lugar. Y hay algo ciertamente paradójico en esta afirmación, pues, para la mayoría de los habitantes de la ciudad, se trata de un lugar desconocido, al que nunca fueron, al que probablemente nunca vayan y, fundamentalmente, al que van a evitar por todos los medios ir. Ubicado en la periferia pobre de la ciudad, alejado de los circuitos cotidianos de la mayoría de los habitantes, y altamente estigmatizado en cuanto espacio atravesado por la pobreza y asociado con la criminalidad, Puente de Fierro es un punto de referencia en cierta geografía simbólica que regula prácticas, significaciones y afectos en la ciudad. De esta manera, en ese mapa simbólico más o menos compartido, donde los distintos lugares que componen la ciudad adquieren valoraciones diferenciales al relacionarse unos con otros, Puente de Fierro constituye uno de los nombres propios habituales para hablar de la periferia, de sus problemas y de sus riesgos.

Con la fuerza de la reiteración y de la recurrencia, por medio de "historias de baja intensidad" sobre carencias, delitos y conflictos, la prensa gráfica local ha colaborado con construir un "mapa del des- 
orden" (Caimari, 2012), que tiene Puente de Fierro como uno de sus locus habituales. Esto ayuda a entender por qué, independientemente del grado de conocimiento y de vínculo cotidiano con el barrio, Puente de Fierro es un lugar. Sin embargo, Puente de Fierro no solo es un lugar por ser una de las referencias recurrentes de la prensa gráfica local cuando se trata de ponerle un nombre y otorgarle una ubicación precisa al temor, al peligro y a la pobreza. Es un lugar por ser un espacio intensamente apropiado, producido y significado a lo largo del tiempo, lo que le ha otorgado una identidad característica, así como lo ha transformado en un campo de batalla por sus sentidos, por su historia y por sus usos.

La invitación a participar en un taller sobre espacio y memoria en la Universidad Libre de Berlín ${ }^{1}$ constituyó el estímulo para "desempolvar" algunos registros etnográficos producidos durante el trabajo de campo desarrollado en la periferia urbana de la ciudad de La Plata entre 2007 y 2009, muchos de los cuales estaban agrupados bajo el código "lugar", esperando el momento para ser interrogados. Se trata, en efecto, de los materiales sobre los que se reflexiona en este artículo. En este sentido, me gustaría comenzar con un fragmento de mis notas, correspondiente a uno de los primeros días que estuve en el campo:

Daniel me cuenta que el barrio se creó en 1994 a partir de la ocupación de tierras pertenecientes al ferrocarril desactivado. Cuando llegaron, la zona era un descampado, y desde entonces no ha hecho más que crecer. Mientras me relataba los orígenes del asentamiento, fuimos caminando hasta el Puente de Fierro, una antigua estructura de acero de 40 metros de largo y 5 metros de alto de un ramal de ferrocarril abandonado que le da nombre al barrio, y que inmediatamente asocié a ese futuro pasado que transmite toda arquitectura industrial desmantelada, símbolo de lo que ya no es. Vemos sobre las bases de ladrillo que sostienen el puente gran cantidad de orificios producidos con armas de fuego. Para muchos se trata de indicios de fusilamientos realizados en el puente durante la última dictadura militar, cuando la zona era un descampado, con solo algunas quintas cercanas. Daniel refiere a relatos de los viejos pobladores sobre escuchar disparos por las noches y personas desparecidas. Mientras mirábamos el puente, un hombre con una carreta tirada por un caballo juntaba cartones y desperdicios aún utilizables en el basural que hay debajo del puente y que continúa más allá del terraplén, el cual funciona como límite del asentamiento, mientras varias mujeres con carritos manuales buscaban leña y otros combustibles. Vimos también tres camiones que salían y otros que entraban al basural.
La sensación que me produjo llegar a Puente de Fierro fue pensar en dicho asentamiento como producto de la confluencia de tres procesos asincrónicos: la desarticulación de los trenes que comenzó en la zona a partir de 1970, la dictadura militar iniciada en 1976, que dejó sus huellas de manera particularmente fuerte en toda la ciudad, incluso en sus espacios menos esperados y conocidos, y la transformación de la estructura social y productiva de la Argentina neoliberal, que forzó a gran cantidad de personas desocupadas a la migración a los centros urbanos. La escena a la que asistía, palimpsesto donde se acumulan, como capas sedimentarias, marcas de estos procesos y de sus destiempos -simultáneamente asentamiento precario, basural, lugar de la memoria- era, en gran medida, producto de la articulación de tales procesos.

De esta manera, además de una referencia mediática recurrente, Puente de Fierro es un asentamiento popular "ilegal", que a mediados de los años 90 se emplazó sobre una estructura de ferrocarril abandonada en los años 70, devenida basural a cielo abierto, y que en los últimos años, a partir del emprendimiento de militantes políticos y agentes públicos, se busca establecer como "lugar de memoria", pues hay alguna evidencia fragmentaria de que en ese lugar asesinaron a personas durante la última dictadura militar, a la vez que de manera simultánea existen proyectos para transformarlo en "patrimonio histórico", como testimonio de la relevancia de los trenes en la región. Desindustrialización, dictadura, marginalidad, estigma y memoria convergen en este espacio urbano relegado, producto de la ocupación de tierras públicas por parte de migrantes con trabajos informales. Se superponen, en un verdadero palimpsesto urbano, capas sedimentarias de ocupaciones, usos, relaciones y sentidos diversos. Y, dependiendo de los actores involucrados y de los contextos de interacción social, Puente de Fierro significa en consecuencia muchas cosas distintas, cuando no contrapuestas.

En términos analíticos, en este artículo se considera que el concepto de "lugar" articula tres elementos constitutivos: refiere simultáneamente a una localización (materialización de procesos económicos, sociales y políticos en el espacio), a un local (escenario donde se producen relaciones e interacciones sociales) y al sentimiento de lugar (forma en que los actores sociales se vinculan afectivamente con dicho espacio) (Agnew, 1997). En este marco, el proceso de producción de un lugar se caracteriza por su "multilocalidad" y "multivocalidad" (Rodman, 1992). Por esto, la pluralidad de voces y de lugares que convergen en la producción de "un lugar" torna necesario distinguir los "lugares de enunciación" de los "luga-

1. Se trata del Taller Espacios alterados: memorias de la excepción y la vida urbana -debates entre Argentina y México-, que tuvo lugar los días 3 y 4 de diciembre de 2012, donde se expusieron las ideas preliminares que dieron origen a este artículo. 
res físicos", es decir, quién y desde qué lugar (social) habla sobre los lugares (físicos) y de qué modo. El objetivo de este artículo consiste, pues, en describir e interpretar estas lógicas de construcción de lugares y de atribución de significaciones, por medio del análisis de las relaciones de los habitantes con la ciudad y las relaciones entre los habitantes en la ciudad.

\section{Hacia una antropología del lugar}

\author{
"El lugar de estudio no es el objeto de \\ estudio. Los antropólogos no estudian \\ aldeas (tribus, pueblos, vecindarios...); \\ estudian en aldeas" \\ Clifford Geertz, La interpretación de las \\ culturas
}

Un debate que caracterizó a la antropología urbana norteamericana se expresó en la oposición entre una antropología en la ciudad y una antropología de la ciudad (Hannerz, 1986; Signorelli, 1999), donde mientras la primera hace alusión a trabajos antropológicos desarrollados en contextos urbanos que no problematizan la ciudad como artefacto socio-cultural ni se detienen a pensar el lugar de las configuraciones espaciales en la vida social, apareciendo de este modo la ciudad tan solo como telón de fondo o escenario de la acción social, la segunda -en las posiciones exclusivistas, la "verdadera" antropología urbana- toma como foco de análisis la ciudad, ya sea que se la entienda "como realidad espacial y social que genera y condiciona actitudes y comportamientos; o bien como realidad espacial y social que se identifica, que está constituida por aquellos comportamientos y aquellas actitudes" (Signorelli, 1999, p. 71).

Es en el marco del debate entre una antropología "en" o "de" la ciudad y, específicamente, en el intento por practicar una "antropología del lugar", que la frase de Geertz podría ser interpretada como una muestra más del habitual y generalizado desdén de la antropología metropolitana -en este caso por parte de una de sus voces más autorizadas- por la cuestión urbana. Sin embargo, si bien a nivel "superficial” esta interpretación podría ser parcialmente correcta, a nivel "profundo" (para utilizar el arsenal de términos geertzianos), la sentencia remite a una cuestión diferente y relevante: no se estudian aldeas, y la aldea, cualquiera que sea su escala y sus características, puede ser el terreno más o menos propicio para formular un problema o una pregunta que en nuestro caso se vincula, paradójicamente, con "las aldeas". Así, para decirlo de manera directa, la frase nos previene contra la tendencia a confundir el lugar de estudio con el objeto de estudio, que en el caso de la antropología urbana es más probable y frecuente ya que, como venimos sosteniendo, toda antropología urbana que se precie de tal debería estudiar ciudades en ciudades, lugares en lugares. Aquello que la frase de Geertz nos fuerza a explicitar es entonces el problema, la pregunta de investigación: ¿qué estudiar en una ciudad determinada, en un lugar específico? E inclusive ¿qué estudiar de la ciudad o de los lugares (en términos genéricos) en una ciudad concreta, en un lugar particular?

Viéndolo desde esta perspectiva, a la vez que nos desafía, la frase de Geertz nos libra del holismo como imperativo disciplinar: la pretensión (imposible) de dar cuenta de la totalidad (De La Pradelle, 2007), y nos alerta contra la equivocación de equiparar un lugar a un sistema (o a una cultura) al que se le asigna un territorio propio y autónomo, con límites claros y precisos, y con una lógica específica que se manifiesta dentro de los límites de dicho territorio; es decir, el error de replicar el isomorfismo entre espacio, lugar y cultura (Gupta; Ferguson, 2000). De esta manera, antes que unicidad estable y cerrada sobre sí misma, "lugar" remite aquí a un espacio de entrecruzamientos, diálogos y conflictos entre diversos y desiguales actores a lo largo del tiempo, lugar que es a la vez condición, objeto y producto de estas relaciones (Agnew, 1997).

Por otro lado, para una "antropología del lugar", no se trata de escoger entre uno de los dos términos de la (a nuestro entender falsa) dicotomía entre antropología en la ciudad y antropología de la ciudad. Aunque solo tardíamente la antropología consideró la ciudad y la vida urbana como objetos legítimos de análisis, desde sus inicios la disciplina pensó el espacio como una dimensión fundamental de la vida social, señalado en distintas perspectivas teóricas (Durkheim; Mauss, 1996; Evans-Pritchard, 1977; Kuper, 2003) el carácter de artefacto socio-cultural del espacio (y también del tiempo), en el doble sentido de ser socialmente producido y, a la vez, marco fundamental que ordena la experiencia social. Por esto, nuestro foco se coloca en el habitar, experiencia que supone relaciones y condicionamientos mutuos entre espacio urbano y prácticas sociales, y nos permite evitar caer tanto en una antropología insensible a la relevancia del espacio en la vida social como en aquella otra que confunde el espacio con la vida social.

En síntesis, en este artículo buscamos conocer los modos de tornar "lugar" un "espacio", es decir, delinear los trazos por medio de los cuales en el proceso social y temporal de habitar un espacio (apropiarlo, producirlo, usarlo, disputarlo) este se carga de sentidos y significaciones diversos, tanto secuenciales (sentidos que suceden unos a otros) como contrapuestos (sentidos contemporáneos, alternativos o en 
disputa). Si identidad, relación e historia (Augé, 1995, 1996) son las características de todo "lugar antropológico", el desafío consiste en mostrar el proceso social y temporal por el cual un espacio adquiere determinado sentidos y deviene lugar. Proponemos, de esta manera, un diálogo constante - un incesante ir y venir - entre el "lugar" y el "espacio" tal como los entiende De Certeau (2000): el espacio como lugar practicado, como apropiación, actualización y transformación del lugar.

\section{Habitar: temporalidades y relaciones sociales}

La ciudad de La Plata, capital de la provincia de Buenos Aires, fue diseñada a fines del siglo XIX como una obra cerrada, acabada. Debía ponérsele un límite y un marco a la cuadrícula, recortar la ciudad de la no ciudad, separar la cultura de la naturaleza, la civilización de la barbarie. Esa función se le asignó a la Avenida de Circunvalación, verdadera "muralla horizontal perforada" (Garnier, 1992), compuesta por una estructura vehicular de doble mano, de cien metros de ancho y veinte kilómetros de longitud, que delimita el damero urbano, permite circular en torno al mismo y tiene puntos de comunicación con el exterior. La historia urbana de la ciudad, sin embargo, se caracterizó por una constante tensión entre el plano ideal, estático y sincrónico (la ciudad dada de una vez y para siempre), y el proceso real, dinámico y diacrónico de urbanización, que supuso tanto una fuerte suburbanización desde mediados del siglo XX (actualmente $2 / 3$ de sus 600000 habitantes residen en la periferia) como una creciente conurbación con la ciudad de Buenos Aires.

El trabajo de campo etnográfico se desarrolló en la zona que se conoce como Altos de San Lorenzo, ubicada al sudeste del casco fundacional de la ciudad de La Plata, con una población cercana a los 40000 habitantes. Se trata del sector de la periferia urbana consolidado de manera más tardía, que se localiza en el extremo opuesto al sector con mayor desarrollo de la ciudad, representado por el eje Buenos Aires-La Plata. Su posición singular con respecto a la ciudad hace que se encuentre a un "costado" y "marginado" de las mayores inversiones urbanas y de las principales vías de comunicación. Comenzó a poblarse lentamente a partir de los años 1940 y 1950, producto de los primeros loteos de terrenos en la zona, adquiridos por empleados del ferrocarril (adyacente a la localidad se encontraba la Estación Central del Ferrocarril Provincial), trabajadores de los frigoríficos de Berisso y diversos cuentapropistas. Con la crisis del ferrocarril y los frigoríficos en la década de 1970, la zona se es- tancó, y recién a partir de los años 90 su población y su entramado urbano se expandieron, fundamentalmente por la creación de asentamientos y barrios precarios ubicados mayoritariamente en tierras públicas.

Como resultado de este proceso se estableció una clara distinción para los habitantes de la periferia entre el "barrio" (zona más cercana a la ciudad, de poblamiento temprano, habitada por asalariados propietarios de los terrenos) y el "asentamiento" (zona más alejada de la ciudad, de poblamiento reciente, por parte de ocupantes "recién llegados", con vínculos débiles con el mercado de trabajo). De esta manera, en la ocupación de la zona se evidencia lo que Durham denominó "periferia como un proceso", donde "la población más pobre y los recién llegados tienden a localizarse en las franjas del área urbanizada, donde la ausencia de servicios como luz, agua, iluminación, asfalto y alcantarillas hace más barato y accesible el suelo urbano" (Ibid., 2004, p. 388; traducción propia). Y por esto, contra lo que habitualmente supone el sentido común del resto de los habitantes de la ciudad, la periferia no consiste en un espacio homogéneo. Se trata de un espacio heterogéneo, en el que las condiciones económicas, habitacionales y urbanas desmejoran a medida que uno se aleja de la avenida 72 (denominación que adquiere en ese tramo la avenida de Circunvalación, límite del trazado fundacional de la ciudad) hacia el espacio rural, verdadero degradé urbano legible en el tipo y los materiales de las viviendas, la extensión y la calidad de servicios urbanos como agua, cloacas y asfalto, la configuración de la traza urbana de manzanas y calles, el arbolado y el espacio verde disponible, entre otras. Resultado de esta continua expansión de la periferia cada vez "más allá" (y, por lo tanto, cada vez "más lejos") de los límites fundacionales de la ciudad, Puente de Fierro es un "barrio", "villa" o "asentamiento" (dependiendo tanto de quién habla como en qué contextos) creado a mediados de la década de 1990 en los terrenos públicos del ferrocarril abandonado. Debe su nombre a su emplazamiento adyacente al viejo puente de hierro, construido en 1904 como parte de la infraestructura de un cruce ferroviario, cuando la zona estaba completamente deshabitada, conocido desde tiempo antes como Puente de Fierro.

Si nos detenemos en la caracterización del espacio y del proceso de poblamiento, se debe a que estas sucesivas ocupaciones y usos son las que tornan inteligible los sentidos que el lugar adquiere. Se trata del habitar "como el proceso de significación, uso y apropiación del entorno que se realiza en el tiempo" a través de un "conjunto de prácticas y representaciones que permiten al sujeto colocarse dentro de un orden espacio-temporal y al mismo tiempo establecerlo" (Duhau; Giglia, 2008, p. 22-24). Proceso necesariamente "inacabado", mediante el cual los ac- 
tores sociales se sitúan en unas coordenadas espaciotemporales a partir de la relación (representación y uso) del entorno que los rodea y de las relaciones sociales que establecen con otros actores. Del análisis de habitar la periferia en La Plata se desprenden dos cuestiones fundamentales para comprender los sentidos cotidianos de Puente de Fierro: por un lado, los habitantes de la periferia no solo comparten una posición espacial y social desventajosa, sino también una experiencia común (Caldeira, 1984) vinculada con habitar la periferia: la migración hacia la ciudad, el sueño de un lugar propio, las múltiples dificultades vinculadas con la ausencia de infraestructura, los servicios deficientes, las largas distancias por cubrir para acceder al trabajo, la salud y la educación, y la historia del barrio como un paulatino progreso en el acceso a dichos bienes y servicios, constituyen referencias compartidas en los relatos de los habitantes de la periferia, independientemente del momento y de las condiciones en que arribaron. Se mira y se vive la ciudad desde una posición social y espacial, posición en la que se experimentan como parte de la vida cotidiana ciertas cuestiones singulares de ese espacio (y ajenas a otros habitantes de la ciudad), que tienen influencia en los modos de pensarse en relación a la ciudad (en términos nativos, viven "afuera" de la ciudad).

Por otro lado, en la configuración socio-espacial actual se observa una fuerte correlación entre tiempo de residencia y condiciones de vida (Elias; Scotson, 2000), que se expresa en el referido degradé urbano en el cual las condiciones de vida desmejoran a medida que nos alejamos del límite del trazado fundacional de la ciudad, generando clivajes hacia el interior del espacio barrial y minimizando las posibilidades de articulación a partir de la experiencia común de habitar la periferia. Si bien la mayoría de distintos residentes del barrio atravesaron una experiencia similar de habitar el territorio, lo hicieron en momentos distintos y en condiciones desiguales, por lo que se ven recíprocamente como (y en términos sincrónicos son) grupos diferentes.

De esta manera, para quienes comenzaron a poblar la periferia desde mediados del siglo XX por medio del acceso a lotes baratos, Puente de Fierro remite retrospectivamente en sus relatos a un espacio verde y vacío destinado a la recreación y el divertimento, evocado con cierta nostalgia como un "paraíso perdido". Julio, de 60 años, señala que "sigue estando todavía el famoso terraplén, el Puente de Fierro, ahora habitado por villas y ese tipo de cosas, pero en esa época no había nada, todo eso era virgen, pasaba el tren y nos íbamos ahí con los chicos del barrio, en bicicleta, caminando, como sea". Los hijos de Ermelinda, unos años más chicos que Julio, narran historias similares. Marcelo, de 52 años, señala que "era una de las primeras excursiones que uno se animaba a hacer lejos. Era ir lejos. Íbamos caminando, no había habitantes permanentes en esa época", y su hermano Roberto, de 43 años, cuenta que "yo iba a cazar a Puente de Fierro con mis amigos. Esa zona era campo, yo corría liebres. Donde ahora hay asentamientos, yo corría liebres. Me cruzaba algún ciruja de vez en cuando pero no era una mugre como es ahora". Por su parte, Gabriela, de 45 años e hija de una de las primeras familias de la zona, recuerda que "era un lugar de encuentro, íbamos al Puente de Fierro a las tardes a jugar, íbamos con una mamá. Íbamos a cazar pajaritos con la gomera o a pescar, porque por ahí se hacía algún arroyito, alguna lagunita cerca del puente, no había suciedad, este barrio era completamente limpio".

En esos mismos relatos, el cierre del ferrocarril y la dictadura militar se encuentran entre las razones por las cuales Puente de Fierro dejó de ser un lugar de juegos de chicos y de paseo familiar por muchos años. Progresivamente se transformó en un basural a cielo abierto, en un lugar donde se abandonaban autos robados y, bastante más tarde, comenzaron a establecerse los asentamientos, significados como un clivaje en la historia del lugar y en la sociabilidad cotidiana. "E1 problema cambió con los asentamientos que se han ido armando -sostiene Adolfo, de 48 años-, lo que vemos es cada vez más violencia y robos, acá me han entrado un par de veces, por eso debimos poner reja". A diferencia del pasado, "lo que vemos -sostiene Gabriela- es mucha gente extranjera, está invadido por extranjeros". En este sentido, la mayoría coincide con Roberto en que "hace unos veinte años el clima empezó a cambiar. La gente no encontró lugares más céntricos y empezó a asentarse en este lugar". Desde la perspectiva de los antiguos residentes, este proceso se manifiesta en cambios importantes en la sociabilidad barrial, como el desconocimiento y la desconfianza entre vecinos y el incremento de la inseguridad y el temor. "Mi hijo, creo que fue una vez sola [a Puente de Fierro] -cuenta Gabriela-, con mi marido a andar en bicicleta, pero ya después no porque empezó todo lo que era el asentamiento y la basura".

Condensando estos sentidos y sentimientos, en la tapa del primer número de la revista barrial Imágenes de un barrio, publicada en 1995, momento en el que los primeros asentamientos (como Puente de Fierro) habían comenzado a establecerse en la zona, se observa una foto donde se puede ver el Puente de Fierro como fondo y un gran descampado, cubierto de basura y con restos de un automóvil abandonado en el primer plano; el epígrafe señala "cuantos recuerdos debe despertar esta imagen, a los que antaño iban a cazar ranas, de picnic dominguero, o a juntar leña de los matorrales junto al terraplén".

Muy distintos son los sentidos y los sentimientos de quienes viven en Puente de Fierro. Mientras 
los tempranos residentes de la zona cercana al puente contrastan el presente con el pasado en su evaluación del lugar, en un eje temporal cuyos extremos son el "antes" y el "hoy", los habitantes de Puente de Fierro contrastan su actual lugar de residencia con sus lugares de procedencia, por medio de un eje espacial cuyos extremos son el "aquí" y el "allá". En ambos casos, los sentidos del lugar son multiescalares (Lindón, 2005), refiriendo a los lugares pasados, a los dejados atrás, a los deseados y a los temidos. Y mientras para los primeros la evaluación es negativa, los segundos proponen una ecuación matizada: se dejaron afectos y vínculos en el lugar de procedencia y, si bien "la ciudad" no es lo que se imaginaban, "aquí" se consiguieron oportunidades inexistentes "allá" -como acceso a trabajos informales, "ayuda social" por parte de programas estatales, entre otros-, y "hoy" el barrio está mejor que "antes", cuando llegaron y era "todo campo". Por eso, mientras los primeros no lo saben (o no lo imaginan), actualmente también hay chicos que juegan en el puente. Belén, de 11 años, relata "vamos arriba de la montaña [por el puente], o vamos allá atrás, atrás del puente, hay mucha tierra, nos tiramos ahí y nos ensuciamos todo. A veces viene mi familia de Buenos Aires y vamos ahí al puente a jugar con mis primitas", y Johny, de 9 años, me cuenta "juego a la pelota, algunas veces juego a la escondida en mi casa con mi hermano, a veces voy a la montaña”. Al preguntarle el porqué, me responde: "tiene juguetes tirados".

Necesitamos reconocer, entonces, las temporalidades y las espacialidades múltiples involucradas en el proceso de habitar y las relaciones sociales que se entretejen en dicho proceso, que permiten comprender los distintos puntos de vista sobre el lugar. En esta dirección, no alcanza con señalar que los sentidos son diversos y cambiantes -algo que muchas teorías indican- sino desentrañar la lógica relacional (Segura, 2011) que nos ayuda a comprender su variación. Los usos, los sentidos y también los sentimientos sobre un "mismo" lugar están mediados por relaciones sociales establecidas en el proceso social, espacial y temporal del habitar.

\section{Memorias y Patrimonios: huellas, selecciones y olvidos}

Durante el trabajo de campo, además de la creciente visibilización -y estigmatización- mediática de Puente Fierro, identificamos dos grupos de "emprendedores de memoria" (Jelin, 2002) que trabajan desde el presente sobre las significaciones pasadas de Puente de Fierro y, en dicha operación, buscan revertir o cuestionar la estigmatización. Se trata de dos proyectos diferentes, tanto por su escala como por su temática, en los cuales están involucradas instituciones político-culturales, residentes de la periferia y personas que viven en otros lugares de la ciudad. ${ }^{2}$ Ambos tienen en el puente su anclaje material, pero intervienen aplicando claves de lectura diferentes sobre la significación y el pasado del lugar: mientras una construye al puente como "espacio de memoria" vinculado con la última dictadura militar (19761983), la otra lo concibe como "patrimonio histórico" en relación con sus características arquitectónicas e históricas.

De esta manera, ambos proyectos nos muestran que si bien es indudable que los procesos históricos dejan huellas en el espacio urbano, estas en sí mismas no constituyen memoria ni patrimonio, a menos que sean evocadas y ubicadas en un marco que les dé sentido (Ibid., 2012). Contra la habitual naturalización y estabilización de los sentidos de un lugar, es necesario reconocer que "la marca territorial no es más que un soporte, lleno de ambigüedades, para el trabajo subjetivo y para la acción colectiva, política y simbólica, de actores específicos en escenarios y coyunturas dadas" (Jelin; Langland, 2003, p. 4). Dicho de otro modo, si, como sostuvimos respecto de Puente de Fierro, el espacio urbano puede pensarse como palimpsesto (texto urbano que combina en su superficie escrituras de distintos tiempos, borramientos, huellas, superposiciones), esta noción no nos permite conocer el proceso de selección y de ubicación en un relato que les otorgue sentido a esas huellas, el cual es resultado siempre parcial de las prácticas de distintos actores sobre la forma urbana (BINDER, 2012). Así, en el lugar se asiste a un doble movimiento. Por un lado, en su propia materialidad, Puente de Fierro es el producto de capas de historias y sentidos sedimentados que han dejado sus huellas en el espacio: tren, abandono, dictadura, marginalidad, entre otras. Por el otro, identificamos actores e instituciones que desde el presente realizan operaciones de selección, recuperación y olvido de distintos elementos, historias y sentidos.

Vale señalar que las relaciones entre "memoria" y "patrimonio" son complejas y en muchas ocasiones es difícil establecer límites y distinciones precisas entre ambos procesos. En términos analíticos podemos decir que tanto la memoria como el patrimonio son construcciones presentes del pasado y, por esto, suponen ejercicios de selección, escenificación, narración y, por supuesto, olvido y silencio. Sin perder

2. Junto con la representación mediática y la estigmatización social de Puente de Fierro, estos dos proyectos nos recuerdan que, como señalamos al inicio de este artículo, los sentidos de un lugar no son necesariamente producidos de manera exclusiva por quienes lo habitan, siendo necesario distinguir los "lugares de enunciación" de los "lugares físicos", quién y desde qué lugar (social) habla sobre los lugares (físicos). 
de vista estas semejanzas y relaciones entre memoria y patrimonio, en lo que sigue presentamos dos intervenciones sobre el espacio barrial, su arquitectura y su historia que, en términos nativos, fueron tratadas como "memoria" y como "patrimonio" respectivamente. Por medio de una lectura presente del pasado, ambos proyectos proponían revertir la carga simbólica negativa que recae sobre el barrio y sus habitantes, pero mientras el primero apuntaba al futuro a partir de recordar el pasado (memoria), el segundo enfatizaba la necesidad de conocer y conservar el pasado (patrimonio) para revertir la imagen del lugar en el presente.

Puente de Fierro como "Ingar de memoria". Uno de los emprendimientos enfatiza la vinculación del Puente de Fierro con la última dictadura militar y busca transformarlo en un "lugar de memoria". Las voces sobre lo que allí ocurrió durante la dictadura son diversas y fragmentarias. Están, por supuesto, las marcas de disparos de bala en la base del puente, y estas huellas dan lugar a interpretaciones variadas. Quienes residían en los barrios cercanos al puente durante esos años tienen distintas versiones. Para Gabriela, el abandono del puente como lugar de recreación se relaciona de manera directa con la dictadura, pues a partir de la dictadura "no nos dejaron ir más, se decía que cosas raras pasaban en el puente". En cambio, Silvia señala que "en plena dictadura los militares hacían prácticas de tiro en esa zona” y que ella iba con "amigos a cazar pajaritos y nos llevábamos los casquillos de las balas. Nunca se comentó que en esa zona hubiera habido fusilamientos, sí que venían a practicar en ese lugar. Eso sí". Por su parte, los actuales residentes de Puente de Fierro remiten a relatos e historias que circulan sobre el lugar. Daniel, oriundo de la provincia de Jujuy y residente en Puente de Fierro desde mediados de los años 90, señala que "se encontraron los casquillos de bala en el puente y los ancianos que vivían por acá cerca cuentan que cuando pasaba el tren se escuchaba la ráfaga de tiros, los mataban ahí". Por su parte, Rosa, una mujer de 62 años procedente de Chaco que acompañó a Antonio ${ }^{3}$ en la creación del barrio, señala las razones del nombre del barrio: "puente por el puente y fierro por su hermano [el hermano de Antonio], que era el hincha de Gimnasia. En honor al Loco Fierro ${ }^{4}$ le pusimos. Aparte ellos tienen una hermana desaparecida y se corrían versiones de que la mataron ahí y que la tiraron. Eran las versiones vox populi, esas cosas que nunca se pudieron comprobar. Pero es lo que la gente dice".

La dificultad mayor para conocer lo que ocurrió en el lugar durante ese período estriba en que los residentes actuales del barrio llegaron mucho tiempo después. Sin embargo, más allá de las distintas versiones, está confirmado que en el Puente de Fierro, el 24 de diciembre de 1975, unos meses antes del inicio de la dictadura fue hallado colgado el cuerpo sin vida de Ricardo "Patulo" Rave, un militante de 19 años de la Unión de Estudiantes Secundarios (UES), ${ }^{5}$ tiempo después de que 20 hombres armados irrumpieran en la casa familiar en el centro de La Plata y se lo llevaran. Aunque nadie en el barrio se refirió a este evento, consiste en la principal evidencia presentada por distintos proyectos de ley. De esta manera, en el año 2006, con motivo del trigésimo aniversario del golpe de Estado, el Concejo Deliberante de la Municipalidad de La Plata sancionó la ordenanza municipal $N^{\circ}$ 10076 por la cual declaró "Patrimonio Histórico al "Puente de Fierro" ubicado en la calle 90 entre 29 y 30", a la vez que se comprometía a confeccionar y colocar una placa con la inscripción: "Aquí se cometieron crímenes de lesa humanidad. Si todos nos acordamos no volverá a suceder". Al año siguiente, el Senado y la Cámara de Diputados de la Provincia de Buenos Aires sancionó la ley por la cual se designaba "con el nombre de Ricardo "Patulo" Rave" y se declaraba "Bien Patrimonial de Valor Simbólico incorporado definitivamente al patrimonio cultural de la Provincia de Buenos Aires, al puente ferroviario ubicado en las calles 131 y 90 de la ciudad de La Plata, hoy conocido como "Puente de Fierro".

Las "tareas de reconstrucción y limpieza en la zona" y la colocación de la "placa recordatoria" que estaban en los fundamentos de las leyes nunca se realizaron, así como muy pocos habitantes de la ciudad (y del barrio) conocen esta historia, situación que contrasta con la fuerte visibilidad que tienen en la ciudad otros "lugares de memoria". Puente de Fierro continúa siendo un lugar desconocido y temido. Y las dificultades para que se consolide como un "lugar de

3. Antonio es uno de los referentes del Partido Justicialista en Altos de San Lorenzo desde la década de 1980 y el organizador de gran parte de las tomas de tierra que dieron origen a "barrios" o "asentamientos" como Puente de Fierro a partir de mediados de la década de 1990.

4. El "Loco Fierro" fue el líder emblemático de la "barra brava" de Gimnasia y Esgrima de La Plata, uno de los dos clubes de fútbol de la ciudad que participan del torneo de Primera División de la Asociación del Fútbol Argentino. La explicación del nombre del barrio propuesta por Rosa es sin dudas discutible, más teniendo en cuenta los testimonios que remiten a una profundidad temporal mayor sobre la denominación de la zona como Puente de Fierro. Parece más probable, en cambio, que el "Loco Fierro" deba se nombre al puente que a la inversa.

5. La Unión de Estudiantes Secundarios tuvo un papel fundamental en las luchas por el Boleto Estudiantil. Con posterioridad al asesinato de Ricardo "Patulo" Rave, y en el marco de esa demanda por parte de los estudiantes, el 16 de septiembre de 1976 se produjeron en La Plata los secuestros de estudiantes de la UES en lo que se conoce como "La noche de los lápices". Una de las organizaciones sociales y políticas más importantes de de Puente de Fierro inauguró en 2003 un comedor denominado "María Claudia Falcone", en memoria de una de las estudiantes desaparecidas esa noche en la ciudad, y es una de las organizaciones que promueve que el sitio se transforme en lugar de memoria. 
memoria" de la ciudad nos remiten directamente a su posición geográfica segregada y a su estatus simbólico devaluado.

Puente de Fierro como "patrimonio". Durante el año 2004, la escuela especial N 532 de Altos de San Lorenzo recibió una invitación de la Federación Argentina de Amigos de Museos (FADAM) para que sus alumnos participaran en un concurso denominado "Descubriendo nuestro patrimonio cultural y artístico". La idea de los docentes de la escuela fue hacer un trabajo con los alumnos mostrando el patrimonio cultural y artístico del barrio. De manera ciertamente sintomática tanto de la propia imagen del barrio como de los sentidos con los que se asocia al patrimonio, cuando se decidieron a participar les surgió la pregunta: ¿cuál es el patrimonio del barrio? Como relató Olga, una de las maestras que coordinó el proyecto, cuando recibieron la invitación, se pusieron a pensar sobre qué hacer pues "es un barrio nuevo, sin historia; acá no hay casas viejas ni monumentos". María, la asistente social de la escuela que también participó en el proyecto recuerda lo mismo: "nosotros pensábamos que acá no teníamos nada típico que fuera patrimonio arquitectónico ¿qué tenemos nuestro?". Finalmente se decidieron por hacer el trabajo sobre el Puente de Fierro ya que "está en Altos de San Lorenzo" y, como dijo Olga, "acá es muy conocido. Yo trabajo acá desde hace 15 años. Antes parecía que el puente estaba lejos, en el campo, y ahora hay casas hasta en el puente".

El trabajo titulado "Puente de Fierro", realizado por los alumnos de la escuela bajo la coordinación de las maestras y la colaboración de antiguos empleados del ferrocarril que formaron parte de los primeros habitantes de la zona, se centró en el puente como patrimonio histórico fundamentado en su antigüedad (creado en 1904), las características constructivas (hierro acerado importado de Inglaterra) y las funciones del puente (cruce de ramales en el antiguo sistema ferroviario regional), obteniendo el segundo premio en el certamen y teniendo cierta repercusión mediática. Como podía leerse en una gacetilla de prensa de la Dirección General de Cultura y Educación (2007), "los alumnos lograron reformular una asociación negativa de un ícono de su barrio, el "Puente de Fierro", revelando su otro significado de carácter vital. El primero aludía a la muerte, porque allí se mataba gente y luego se arrojaban cuerpos sin vida durante la dictadura, mientras que el nuevo concepto remite a la vida, al dejar al descubierto que ese mismo puente permitía el paso del tren lechero que abastecía a la ciudad".

Todo patrimonio es resultado de un proceso de selección, visibilización y resignificación y, por lo tanto, también todo patrimonio tiene sus silencios y sus olvidos. El énfasis en la antigüedad, en la monu- mentalidad y en el glorioso pasado del puente, incluso la contraposición entre vida y muerte, contenidos que no están en el trabajo original, sino en las coberturas mediáticas posteriores, silencian una parte importante de lo que Puente de Fierro es, borrando a las personas que construyeron un precario -pero siempre en franco progreso- "barrio", "asentamiento" o "villa".

El dilema al que se enfrentan este tipo de intervenciones sobre el espacio urbano consiste en ¿cómo construir un "espacio de memoria" o celebrar el "patrimonio histórico" en un lugar estigmatizado, temido y evitado, donde un número importante de sus habitantes viven en condiciones de extrema pobreza? ¿Cómo revertir las cargas negativas que se asocian con un lugar espacialmente segregado y simbólicamente devaluado? ¿Y cómo, en el intento, no replicar desigualdades o exclusiones que en cierta medida se buscan revertir?

\section{Palabras finales}

Los lugares no tienen sentidos intrínsecos, tampoco lógicas plenamente autónomas. No consisten en espacios cerrados o replegados sobre sí mismos, sino que, por el contrario, los percibimos como únicos, específicos y delimitables en tanto producto de entrecruzamientos y relaciones de escalas diversas que se producen en -y acerca de- ellos y de su relación con otros lugares.

Si todo lugar es "excéntrico" o "descentrado", en el caso de los espacios residenciales de los sectores populares esta característica adquiere una relevancia mayor. Los diferenciales de poder y de prestigio afectan, entre otras cosas, las capacidades y las potencialidades para manejar la imagen de sí y del entorno propio. Sin embargo, las significaciones sobre Puente de Fierro no se agotan en las hetero-identificaciones (mediáticas y sociales) mayormente negativas que se construyen sobre dicho lugar en la forma de "estigmas territoriales" (Wacquant, 2007) que afectan la experiencia urbana de sus residentes (Segura, 2012).

Por el contrario, al acercarnos a la vida cotidiana que se despliega en el espacio barrial y que involucra tanto a los residentes como a otros actores e instituciones sociales, identificamos otros procesos y dinámicas relevantes para comprender la construcción y los sentidos del lugar, algunos de los cuales son una respuesta directa a la interpelación que el propio estigma genera, otros que solo tangencialmente se relacionan con aquel.

Se suele reiterar -un tanto mecánicamente- que un lugar es un espacio construido, apropiado, cargado de sentido. El énfasis otorgado al habitar como proceso de apropiación y significación del entorno 
buscó reponer los trazos fundamentales por los cuales un espacio devino y, en tanto proceso abierto e inacabado -como muestran las intervenciones sobre la "memoria" y el "patrimonio"-, continuará deviniendo lugar, con sentidos y valoraciones cambiantes, alternativas o en abierta disputa. En este aspecto, nos gustaría remarcar la importancia de la temporalidad y de las relaciones sociales implicadas en el habitar. Por esto, personas que comparten una "experiencia común" vinculada con habitar la periferia se perciben como grupos distintos y los "antiguos" residentes, que recuerdan con nostalgia al Puente de Fierro como un pequeño "paraíso perdido" donde pasar el tiempo libre, construyen a los habitantes "recién llegados" de Puente de Fierro como intrusos, fuera de lugar, reproduciendo los estereotipos que habitualmente recaen sobre ellos en otros ámbitos sociales de la ciudad. El habitar, entonces, remite tanto a la relación de los actores con el entorno como a las relaciones entre actores sociales en el entorno. Solo reponiendo la trama de relaciones de la periferia urbana y la temporalidad del habitar es posible comprender las variaciones en la significación de un lugar que es visto externamente como homogéneo.

Por otro lado, del análisis de los emprendimientos relativos a la "memoria" y al "patrimonio" del lugar, más allá de las selecciones, los silencios y los olvidos ya señalados de cada uno de ellos, se desprende que es necesario tener presente que "revertir los sentidos dominantes sobre un lugar y, a la vez, reponer otros sentidos a través de "marcar y conservar el espacio" es un proceso que se desarrolla en el tiempo, que implica luchas sociales, y que produce (o fracasa en producir) esta semantización de los espacios materiales" (Jelin; Langland, 2003). En otras palabras, ¿alcanza con marcar el espacio para transformar o revertir los sentidos de un lugar? ¿Hay certezas acerca de la eficacia de tales operaciones? La paradoja emerge con claridad (Segura, 2013): necesitamos el espacio para recordar y para construir un lugar y, a la vez, lo que se recuerde, lo que se olvide y lo que ese lugar signifique, no dependerá exclusivamente de lo que inscribamos en el espacio.

\section{Referencias}

AGNEW, J. Representing space: space, scale and culture in social science. In: DUNCAN, James; LEY, David (Comp.). Place/Culture/Representation, London: Routledge, 1997.

AUGÉ, M. Hacia una antropología de los mundos contemporáneos. Barcelona: Gedisa, 1995.

. Los "no lugares". Barcelona: Gedisa, 1996.

BINDER, J. Debates de memoria. El muro de Berlín como espacio conflictivo. In: HUFFSCHMID, A.; DURAN, V. (Ed.). Topografías conflictivas: memorias, espacios y ciudades en disputa. Buenos Aires: DAAD/Nueva Trilce, 2012.

CAIMARI, L. Mientras la ciudad duerme. Pistoleros, policías y periodistas en Buenos Aires, 1920-1945. Buenos Aires: Siglo XXI, 2012.

CALDEIRA, T. A política dos outros. O cotidiano dos moradores da periferia e o que pensam do poder e dos poderosos. San Pablo: Editora Brasiliense, 1984.

DE CERTEAU, M. La invención de lo cotidiano I. México: ITESO, 2000.

DE LA PRADELLE, M. La ciudad de los antropólogos. Cultura urbana, Santiago de Chile, n. 4, 2007.

DUHAU, E.; GIGLIA, A. Las reglas del desorden. Habitar la metrópoli. México: Siglo XXI, 2008.

DURHAM, E. A sociedade vista da periferia. In:

A dinâmica da cultura. Brasil: Cosac Naify, 2004.

DURKHEIM, E.; MAUSS, M. Sobre algunas formas primitivas de la clasificación. In: Clasificaciones primitivas ( $y$ otros ensayos de antropología positiva). Barcelona: Ariel, 1996.
ELIAS, N.; SCOTSON, J. Os Estabelecidos e os Outsiders. Río de Janeiro: Jorge Zahar Editor, 2000.

EVANS-PRITCHAD, E. Los nuer. Barcelona: Anagrama, 1997.

GARNIER, A. El cuadrado roto. Sueños y realidades de La Plata. La Plata: LINTA/ CIC, 1992.

GEERTZ, C. La interpretación de las culturas. Barcelona: Gedisa, 1997.

GUPTA, A.; FERGUSON, J. Mais além da cultura: espaço, identidade e política da diferença. In: ARANTES, A. (Org.). O espaço da diferença. Campinas: Papirus, 2000. HANNERZ, U. La exploración de la ciudad. Hacia una antropología urbana. Buenos Aires: Fondo de Cultura Económica, 1986.

JELIN, E. Los trabajos de la memoria. Madrid: Siglo XXI, 2002.

Militantes y combatientes en la historia de las memorias: silencios, denuncias y reivindicaciones. In: HUFFSCHMID, A.; DURAN, V. (Ed.). Topografías conflictivas: memorias, espacios y ciudades en disputa. Buenos Aires: DAAD/Nueva Trilce, 2012.

; LANGLAND, V. Introducción. Las marcas territoriales como nexo entre pasado y presente. In: Monumentos, memoriales y marcas territoriales. Madrid: Siglo XXI, 2003.

KUPER, H. The Language of Sites in the Politics of Space. In: LOW, S.; LAWRENCE-ZUÑIGA, D. The Anthropology of Space and Place. Oxford: Blackwell Publishing, 2003. 
LINDÓN, A. Figuras de la territorialidad en la periferia metropolitana: topofilias y topofobias. In: REGUILLO, R.; GODOY, M. (Ed.). Ciudades translocales: espacio, flujo, representación. México: ITESO/SSRC, 2005.

RODMAN, M. Empowering place: multilocality and multivocality. American Anthropologist, s.1., n. 94, p. 640656, 1992.

SEGURA, R. La trama relacional de la periferia urbana en la ciudad de La Plata. La figuración establecidos-outsiders revisitada. Revista Publicar en Antropología y Ciencias Sociales, s.1., n. 10, p. 85-106, 2011.
Elementos para una crítica de la noción de segregación residencial socio-económica: desigualdades, desplazamientos e interacciones en la periferia de La Plata. Quid 16, s.1., n. 2, p. 106-132, 2012.

. La ciudad, la memoria y el olvido. Café de las ciudades, s.1., n. 126, 2013.

SIGNORELLI, A. Antropología urbana. México: Anthropos, 1999.

WACQUANT, L. Los condenados de la ciudad. Guetos, periferias y Estado. Buenos Aires: Siglo XXI, 2007.

\title{
Os sentidos do lugar. Temporalidades, relações sociais e memórias em um bairro segregado de La Plata (Argentina)
}

\section{Resumo}

Com um trabalho etnográfico em "Puente de Fierro", bairro segregado e estigmatizado na periferia da cidade de La Plata (Argentina), este artigo analisa o processo de atribuição de significados pelo qual um "espaço" se torna "lugar". Coloca o foco em dois aspectos fundamentais para compreender os significados do lugar. Por um lado, descreve a habitação como um processo social, espacial e temporal, de construção de vínculos com o espaço e com outros atores sociais. Por outro lado, analisa dois projetos contemporâneos (um sobre "memória”, outro sobre "patrimônio") que procuram inverter os sentidos dominantes sobre o lugar. O "lugar" é uma área de ligações cruzadas, diálogos e conflitos entre diferentes atores ao longo do tempo, bem como uma condição, um objeto e um produto dessas relações. É algo aberto e inacabado, com mudança de significados e de alternativas, ou com sua contestação.

Palavras-chave: lugar, habitar, temporalidades, relações, memória.

\section{The senses of place. Temporalities, social relations and memories in a segregated neighborhood of La Plata (Argentina)}

\begin{abstract}
This paper analyzes the process of attribution of meanings by which a "space" becomes a "place" using an ethnographic study on Puente de Fierro, a segregated and stigmatized neighborhood on the outskirts of the city of La Plata (Argentina). It focuses on two fundamental aspects in order to understand the meanings of the place. On the one hand, it describes habitation as a social, spatial and temporal process, as the building of links with space and other social actors. On the other hand, it analyzes two contemporary projects (one on "memory", the other on "heritage") which seek to reverse the dominant feelings about the place. The "place" is an area of crossover links, dialogues and conflicts between different actors over time, as well as a condition, object and product of these relationships. It is an open unfinished process with changes in meanings and alternatives or their contestation.
\end{abstract}

Keywords: place, inhabit, temporalities, relations, memory.

Data de recebimento do artigo: 30/01/2013

Data de aprovação do artigo: 16/05/2013 